\title{
Gender Perceptions of Psychological Empowerment in The Workplace: A Comparative Analysis from Two Cultures
}

\author{
Greg-Victor Chidi Obi, Ph.D. \\ Ohio University-Chillicothe Campus \\ 101 University Drive, Chillicothe, OH 45601 USA \\ Phone: (740) 774-7703 \\ Email: obi@ohio.edu \\ USA
}

\section{A R T I C L E I N F O}

Article history: Article

Received: $\quad 14$ June 2021

Revised: $\quad 8$ July 2021

Accepted: $\quad 10$ July 2021

DOI: $10.47742 / i j b s s r . v 2 n 7 p 1$

\section{A B S T R A C T}

This study investigates how female and male workers perceive feelings of Psychological Empowerment (PE), using respondents from two different countries with dissimilar cultural power dynamics. Two hundred ten non-managerial bank workers from Nigeria and the United States were selected for this study. A comparative quantitative method was used for this study. Statistical analyses were performed using both spreadsheets and SPSS.

My key research question is designed to determine if there are differences in how female and male employees perceive Psychological Empowerment. Data analysis indicates that in both countries combined, and individually, there is a statistically significant difference in the perception of PE between the female and male respondents. Hence, I propose that the first step toward achieving power equity amongst both genders is to first understand how women and men perceive empowerment at a personal level (Psychological Empowerment).

Keywords: Psychological Empowerment, Nigeria, United States, Perception, Gender, Power-equity.

\section{INTRODUCTION}

Organizations across the world have long recognized that a pool of skilled and efficient human resources is considered the most important capital and often the most difficult to copy of an organization's core capacities (Dess, Eisner, Lumpkin, \& McNamara, 2014). It is the organization's employees that help in improving functions, performing organizational duties, promoting quality, and productivity; hence, organizational growth and development depend on the organization's human capital (Lawler III, 2015).

In the face of the growing demand for gender equity in corporate power structures, business and organizational leaders must review old methods and practices or find new ways to maximize their employees' talents to ensure organizational profitability and success. Irrespective of the former, organizations still seem to lag in leveling the playing field for both genders. Given this seeming lethargy in organizations, this study aims to discover if there may be a difference in how women and men perceive power at a personal level.

The findings from this study indicate that there is a statistically significant difference in how female and male employees perceive Psychological Empowerment. Such a finding is very important at this stage of the global society, rife with the demand for equity in compensation and comparable worth for both genders in the workplace. There seems to be the indication that employees (mostly women) who have experienced inequity in terms of promotion, pay, etc. tend to have issues with self-esteem in the long run (Yoshino \& Smith, 2013).

\section{LITERATURE REVIEW}

\section{Psychological Empowerment (PE)}

Conger and Kanungo (1988) were the first to introduce the psychological perspective of empowerment, arguing that empowerment would lead to employees showing greater resourcefulness and feelings of self-efficacy (Bandura, 1986). Thomas and Velthouse (1990) expanded upon this work by articulating a more complete theoretical framework for psychological empowerment. Thomas and Velthouse identified meaning, self-determination, competence, and impact as the set of employee task assessments associated with intrinsic task motivation which are elements or dimensions of psychological empowerment.

Although the dimensions of empowerment have distinctive theoretical meanings, conceptually they are collectively related to form a motivational force that guides and energizes individual work behavior (Spreitzer, 1995; Thomas \& Velthouse, 1990). The four dimensions of psychological empowerment - meaning, self-determination, competence, and impact - have also been found to be positively correlated and are positively related to work-related outcomes, such as job satisfaction and job performance (Seibert, Gang, \& Courtright, 2011). Seibert et al. (2011) postulated that all the four psychological empowerment variables were collectively associated with job outcomes more strongly than each of the 
Vol: 2, Issue: 7

July/2021

https://ijbssrnet.com/index.php/ijbssr

DOI: http://dx.doi.org/10.47742/ijbssr.v2n7p1

http://iarpnet.org/

dimensions separately. Hence, researchers have often examined individual empowerment as a single composite of the four dimensions (Chen et al., 2007; Spreitzer, 1995; Zhang \& Bartol, 2010). Psychological empowerment has been conceived as a state or frame of mind, Spreitzer (1995) in her study of the concept of psychological empowerment, noted that psychological empowerment is:

A motivational construct evidencing an active orientation to work and consisting of four cognitions: self-determination, meaning, competence and impact. Self-determination is the perception that one has the freedom to act at work. Competence refers to the perception of one's confidence to perform jobrelated tasks. The impact is the perception that one has a significant influence on what happens in one's work situation. And, meaning is the value of a work goal or purpose, judged about an individual's ideals or standards ( $p$. 1443).

Contributing to the research, Menon (1999, 2001) sought to find a more integrative approach to understanding PE. Menon concludes that PE is a cognitive state that is evidenced by the empowered person's ability to have a perception of control over one's daily work routine, a perception of competence over the work one does, as well as a perception of internalization of the goals of the organization.

Furthermore, Yukl (2013) notes that the theory of PE is an endeavor to explain situations that are likely to impact the probability of success or failure of empowering people. Yukl seems to argue that the extent of the empowerment's success may well lie within the hands of the individual being empowered since the individual's psychological disposition will, to a large extent, define the individual's reception and use of the power so given. Yukl concludes that "delegating responsibility for a more significant task will not be empowering if people lack the skills and knowledge to perform the task successfully and are worried about failure" (p. 112).

Results from a study of 106 resident physicians on psychological safety, perceived power distance, leadership inclusiveness, and intention to report adverse events in a midAtlantic teaching hospital, Appelbaum, Dow, Mazmanian, KJundt, and Appelbaum (2016) observed that empowerment is an exchange, a relationship that involves the voluntary givingup and/or sharing of power or authority by a leader or leadership group which within organizations includes supervisors, who are most times senior executives and in some cases middle level managers, and the voluntary acceptance by subordinates of that which is being offered to make decisions that affect their job.

In a study of the moderating role of psychological empowerment and burnout in Chinese nurses $(n=244)$, Meng, Jin, and Guo (2016) found that psychological empowerment was a sign of the relationship between structural empowerment and burnout. The implication here then is that nurse managers, and indeed other managers of people must develop methods to enhance subordinates' sense of psychological empowerment as a way to avoid burnout in their jobs.
As a practical construct, the question then is why do leaders need to empower their subordinates? What advantages does it bring to organizations that empower their employees at various levels? And how does one empower a diverse workforce of people from different cultures?

\section{Psychological Empowerment from a Global context}

Several studies have demonstrated that to a large extent most management and leadership practices are limited to or enhanced by the climate of the organizations and that they can also become antecedent to the climate that subsists in the organization (Bowen \& Ostroff, 2004; Chen et al., 2007; Foster \& Fenwick, 2015; Islam, Khan, \& Bukhari, 2016). Additionally, research has shown that empowerment, just as other management and leadership practices, is moderated by the culture within which it is practiced or the cultural background of the individuals empowered (Ahmad \& Oranye, 2010; Shah, 2015; Yip, 2004). In a survey questionnaire study conducted in a U.S. subsidiary in East Malaysia with 118 respondents, Ismail et al (2011) found that empowerment acted as a mediating variable in the relationship between transformational leadership and organizational commitment. It is of significance to note that Ismail, et al.'s study was conducted with non-western subjects working in a non-western organization, thus confirming that even for such organizations when leaders implement:

"Transformational process via individualized consideration, individualized influenced attributes and individualized influenced behavior to achieve the organizational strategy and goal", in such circumstance the study further concludes that "the majority of the employees perceive that such leadership practices had increased their empowerment in implementing organizational functions" (p. 100).

In a comparative study on empowerment, job satisfaction, and organizational commitment whose subjects were 556 registered nurses in Malaysia and England, Ahmed and Oranye (2010) found that there were differences in the level of nurses' empowerment, job satisfaction, and organizational commitment between the two countries. Nurses in the Malaysian hospital perceived greater empowerment and commitment than the nurses in the English hospital. However, nurses in Malaysia were less job-satisfied relative to nurses in England.

Ahmed and Oranye (2010) suggest that the most significant factor that determined nurses' job satisfaction in the Malaysian hospital was the level of co-worker interaction-the opportunities presented for both formal and informal contact during working hours. The study found that this co-worker interaction was less in Malaysia; a country the study rated as culturally having a higher power distance. On the other hand, the study found that pay level was the factor that accounted more significantly for job satisfaction amongst the nurse in the English hospital.

In another study by Jeung, and Yoon (2016) in five South Korean organizations $(n=294)$. This three-year study found that a leader's humanity and the environment positively 
https://ijbssrnet.com/index.php/ijbssr DOI: http://dx.doi.org/10.47742/ijbssr.v2n7p1

predicated follower's psychological empowerment, the followers' power distance orientation was a moderating factor on psychological empowerment. The study found that while psychological empowerment did not positively predict organizational commitment, environmental empowerment did. The conclusion by Jeung and Yoon in this study was that future empowerment studies should be clearly defined from the perspective of leader humanity and the environment.

However, Ambad and Bahron (2012) conducted a study that suggests a different viewpoint. Ambad and Bahron's study subjects were 171 construction workers in the Kota Kinabalu area in Malaysia. The study found that employee commitment to their organization rested high on the employees' feeling of empowerment. The findings from Ambad and Bahron's study indicate that when the construction employees were allowed autonomy, freedom, and opportunity in determining how they did their job, feelings of organizational commitment were higher; hence the workers put their best effort to ensure the sustainability of the organization. This study additionally confirms that since employees are directly involved in outcomes that affect the organization, the more the individuals are involved in decision-making, the more committed they would be to their organization. The research findings also indicated that the education level and length of service of the workers did not significantly moderate the relationship between psychological empowerment and organizational commitment.

Men, (2011) conducted a study using 223 Chinese workers spanning various industries and found that empowerment dimensions of feelings of competence and feelings of control both predicted the quality of the organization-employee relationship. More importantly, the study finds that feelings of control were more strongly associated with the relationship between the employees and their organizations than did feelings of competence. Men's study found that when the employees are psychologically empowered, they exhibited more confidence in exerting influence, as well as achieving self-fulfillment and meaningfulness in their jobs, thus being more satisfied and committed to the organization. Further findings from this study showed that employees who exhibited higher feelings of psychological empowerment in terms of control ability (autonomy of decision-making regarding their work) were more likely to trust the organization and to agree on the mutual benefit of organizations success is tied to their personal growth and success in the organization.

In recent years most empowerment studies conducted in African countries, and Nigeria in particular, have focused more on the areas of education, healthcare, sociopolitical and socioeconomic views of empowerment, rather than from a management or organizational standpoint. It appears that most of the studies on psychological empowerment conducted within the African continent have been focused on the Republic of South Africa (Kotze, Menon, \& Vos, 2007; Stander \& Rothmann, 2009; Theron, 2010).

Other African studies have been focused on social issues such as gender equality, education of the girl child, infrastructure development, etc. For example, a study by Unterhalter, Heslop, and Mamedu (2013) conducted across northern Nigeria $(n=1,734)$ and northern Tanzania $(n=1,104)$ focused more on the political and socio-cultural challenges girls faced in "claiming" education as opposed to the boys. To Unterhalter, Heslop, and Mamedu empowerment was viewed as "how structural gendered inequalities in the political economy and socio-cultural formations constrain the capacity of girls inside and outside school to claim the rights promised by education" (p. 566).

A study conducted in Malawi and Bangladesh focused on the inequality between female and male workers and socioeconomic opportunities that are available to the different genders irrespective of the gains made in educating girls over the years in the two counties (Chisamya, DeJaeghere, Kendall, \& Khan Marufa, 2012). Corroon, et al (2014) study focused on investigating whether women's empowerment in urban Nigerian settings is associated with the way family planning methods are used as well as maternal health behaviors. The study which spanned a little over a year surveyed 16,144 women aged 15-49 across six cities with a sample $(n)$ of 8,834 also examined whether different effects of empowerment existed based on the region where the respondents resided. For Corroon, et al.'s study empowerment was conceived from four dimensions: 1) economic freedom 2) attitudes towards domestic violence 3) partner prohibitions, and 4) decision-making. Interestingly, the study finds a disparity between how respondents in Northern Nigeria exercised more control on family planning decisions from how those in the South. For instance, the study found that women (respondents) in the south reported being more empowered over such decisions. It is important to note that the Northern parts of Nigeria have a higher power distance, more masculine oriented, and more feudal in the relationship between men and women and between leaders and followers.

A significant departure from most other empowerment studies in Nigeria is by Arogundade and Arogundade (2015) which examined empowerment from an organizational management discipline. The study by Arogundade and Arogundade focused on finding if there is a relationship between psychological empowerment and employees' career satisfaction; and if so, to what extent the various dimensions of psychological empowerment (meaning, competence, self-determination, and impact) impacted on employees' career satisfaction?

Arogundade and Arogundade's (2015) study holds significance with this current study in that it was carried out with respondents in the Lagos State of Nigeria, where this study was conducted, and using respondents from both for-profit and notfor-profit organizations. It utilized a simple random sampling technique to select three hundred participants $(M=151 ; F=149)$. The instruments used in this study were the Psychological Empowerment Scale (PES) and Career Satisfaction Scale (CSS), while a simple linear regression was used to analyze the data collected. The findings of the study revealed that together, the four dimensions of psychological empowerment (meaning, competence, self-determination, and 
Vol: 2, Issue: 7

July/2021

https://ijbssrnet.com/index.php/ijbssr

DOI: http://dx.doi.org/10.47742/ijbssr.v2n7p1

http://iarpnet.org/

impact) accounted for $43 \%$ of the variance in career satisfaction. The Beta calculations showed that each of the four dimensions on their own contributed differently to the variance in career satisfaction; competence had the highest variation $(=0.42)$, followed by impact $(=0.33)$, meaningfulness $(=0.16)$, and the lowest was explained self-determination $(=-0.06)$. While the researchers concluded that the implication of their findings substantiated "the importance of creating an empowering work environment to improve employees' work outcomes, sustain greater productivities and enhance career satisfaction" (p. 34). However, the study failed to establish a causal relationship (cause-effect) between the variables, and more importantly the reason for the low variance between self-determination and career satisfaction.

The above-stated limitation of Arogundade and Arogundade (2015) is significant for this study in that this study seeks to find out if the gender of a worker (using Power Distance Index) can show a difference in how people perceive or interpret feelings of psychological empowerment.

\section{Power Dynamics}

Gender schemas, "a set of implicit, or non-conscious, hypotheses about sex differences" (Valian, 1998, p. 2), have been attributed as being responsible for how the professional life of women and men are evaluated, as well as overall gender expectations. One element within an institution's logic is the extent to which gender-specific characteristics are associated with effective leadership capabilities, otherwise referred to as gender-typing. Britton (2000) defined gender-typing as "the process through which occupations (or positions) come to be seen as appropriate for workers with masculine or feminine characteristics" (p. 424) hence most societies, though wrongly, ascribe power as "masculine," seemingly fit only for men and not for women.

The Power Distance Index (PDI) (Hofstede, 1980, 2001) explains that some cultures accept the notion that power distribution is unequal; PDI expresses the attitude of the culture toward these inequalities. Power distance is the extent to which the members of a culture, and by extension institutions and organizations therein, accept that power is distributed unequally. PDI of a country explains how individuals within such a place deal with issues, such as inequalities in terms of prestige, wealth, and power, as well as material acquisitions (Hur, 2006). Both House et al. (2004) and Hofstede (1980, 2001) grouped Nigeria and the United States at opposite ends of the PDI spectrum, placing Nigeria on the high PDI end and the U.S. A. on the low end. This study investigated if there is a difference in how female and male employees, engaged in the same type of work, in both countries perceive feelings of Psychological Empowerment.

\section{METHOD AND RESULTS}

\section{Instrument and Hypotheses}

The research question for this study aimed to find out if there is any difference between how female and male employees perceive feelings of Psychological Empowerment. The Menon
Empowerment Scale (MES) was the instrument utilized for this study. The MES is a nine-item instrument that measures feelings of PE and is scored on a six-point Likert scale (ranging from 1 $=$ strongly disagree to $6=$ strongly agree). Since the MES does not have demographic items I added demographic questions such as age, gender, and educational level of the respondents for the study to be conducted. The range of one's feelings of Psychological Empowerment is then determined by summing the score of each of the nine items. An MES total score of 22 and below indicates low Psychological Empowerment. Moderate PE is valued at scores between 23 and 40, while scores of 41 to 54 indicate high PE.

\section{Data}

The study respondents were drawn from nonmanagerial-level employees of five banks located in Lagos, Nigeria, and four banks located in Northwest Indiana and Southcentral Ohio in the United States. Data was collected over 14 months. There was a total of 105 respondents from the U.S. and 126 from Nigeria that attempted to complete the online survey making a total of 231 . Ten respondents from the U.S. did not fill in at least one item in the survey, making their data unusable. Eleven respondents from Nigeria also were eliminated due to incomplete data. Having removed the incomplete responses, the sample population was 115 from Nigeria and 95 from the United States of America. The number of female respondents from both countries was 126 , which is $60 \%$ of the total sample $(\mathrm{N})$ of 210 respondents, and male respondents were $84(40 \%)$. The Nigerian sample comprised 55 females, making up about $48 \%$ of the 115 respondents, while the male respondents made up the remaining 52\% (60). From the U.S., the total sample size of 95 respondents comprises $71(74.7 \%)$ females and 24 males $(25.3 \%)$.

\section{Result}

To answer the research question, one hypothesis was formulated: Female employees' feelings of $\mathrm{PE}=$ to male employees' feelings of PE.

Using SPSS to calculate the combined gender mean score for both countries revealed that there is a difference in feelings of Psychological Empowerment between the female and male employees in both countries. Comparing the mean score in both countries shows that in both the U.S. and Nigeria, the male respondents reported higher scores on the empowerment scale. Males in the U.S. had a mean score of 42.67 (n 24). The Nigerian male sample had a mean score of 42.83 (n 60). Females respondents in the U.S. had a mean score of 41.34 ( $\mathrm{n} \mathrm{71)}$, while the Nigerian females' mean score was 39.22 (n 55). Combined, the males' mean score for both countries was 42.79 (n 84), while their female colleagues had a mean score of 40.41 (n 126). To determine if the reported difference between the male and female respondents in both countries was statistically significant, a 2 independent sample ttest was conducted to accept or reject the study hypothesis as stated above. The result is presented in table 1 below. 
Table 1: Combined Gender 2 Independent Sample t-test Result

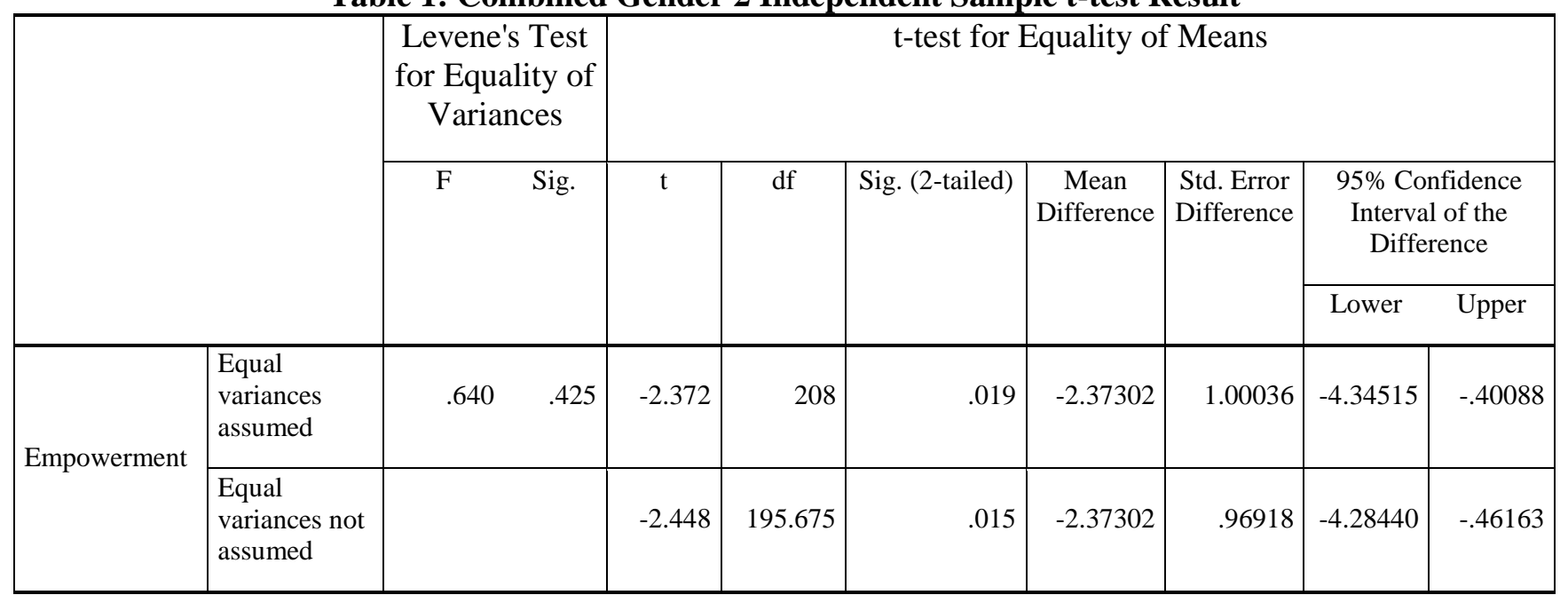

In table 1 above, equal variance is assumed as $.425>.05$. location treated as independent variables and PE as the dependent With a P-value of .019<.05 (alpha), the null hypothesis must be variable was conducted. The result confirms that there is a rejected. This means that there is a statistically significant statistically significant difference between the female difference in feelings of PE between female employees and male respondents' feelings of PE compared and that of the males in employees in both cultures combined.

As a method of cross-checking the above two-sample below. independent $t$-test, a two-way ANOVA with gender and country

Table 2: Culture/Gender/Empowerment Two-way ANOVA

\begin{tabular}{|c|c|c|c|c|c|}
\hline Source & Type III Sum & df & $\begin{array}{c}\text { Mean } \\
\text { Square }\end{array}$ & F & Sig. \\
\hline \multirow{2}{*}{ Corrected Model intercepts } & $423.559^{\mathrm{a}}$ & 3 & 141.186 & 2.810 & .041 \\
V1_Country Location & 304357.271 & 1 & 304357.271 & 6057.191 & .000 \\
V2_Gender & 42.107 & 1 & 42.107 & .838 & .361 \\
& a. & R Squared $=.039$ (Adjusted R Squared $=0.25$ ) & & & \\
& & &
\end{tabular}

\section{DISCUSSION}

Data analysis reveals that there is a statistically significant difference in the reported feelings of Psychological Empowerment (PE) between female and male respondents in the U.S. and Nigeria. The results indicated that the PE of male respondents in both countries was higher than the female respondents. Further, results show that in both the United States and Nigeria, male respondents reported higher feelings of psychological empowerment than their female colleagues. This finding is validated by another study by Speer, Peterson, Armstead, and Allen (2013), which found gender-influenced PE at the intrapersonal level, especially among low-income individuals. The Speer, et al. study focused on the influence of gender on PE across five American communities with a sample population of 562. The results of their study, just like this one, found that male respondents reported higher feelings of PE than female respondents. Valian (1998) notes that in most masculine cultures, women are often trained to think less of power and be less assertive and more docile at the workplace. Hofstede (2001) said both Nigeria's and the United States' cultures have competitive attitudes and the need-to-win mentality. Hofstede's research notes that in countries like these, success is defined as being the winner or the best; such traits are often learned from childhood and continue into the working world.

Hofstede (2001) suggested that both American and Nigerian societies are high on the masculinity spectrum of cultural dimensions. Similarly, Yoshino and Smith (2013) observed that within cultures like the United States, males are often powerfocused and dominant in the workplace; the men are often more conscious of acquiring and using power than their female colleagues. Hence in such masculine-oriented countries, the findings from studies such as this one are very important at the current stage of the global economy, rife with the demand for equity in power, compensation, and comparable worth for both genders in the workplace. Employees (mostly women) who have experienced inequity in terms of promotion, pay, etc. tend to have issues with self-esteem in the long run (Yoshino \& Smith, 2013). In a study conducted amongst Chinese teachers (46 males and 821 females), Wang, Zhang, and Jackson (2013) found that selfesteem was a positive predictor of Psychological Empowerment. To solve these issues, organizations have often resorted to empowerment to create a sense of power and authority for such employees. Hence, this study concludes that empowerment programs will help boost the self-esteem of females in organizations. 
Vol: 2, Issue: 7

July/2021

https://ijbssrnet.com/index.php/ijbssr

DOI: http://dx.doi.org/10.47742/ijbssr.v2n7p1

This study suggests that the first step toward achieving power equity of both genders in the workplace may be understanding the disparity in their feelings toward empowerment. Following this understanding, corrective measures can be taken to empower each group. Policymakers and organizational leaders should strive to provide empowering positions for the female's positions that enable them to feel equal to their male colleagues. Training on overall feelings of Psychological Empowerment should be provided more for female workers.

\section{CONCLUSION AND RECOMMENDATIONS}

Other studies (Kunze, et al., 2013; Lakshmi \& Peter, 2015) have confirmed that both age and gender difference can influence organizational performance and effectiveness; hence, the need to expand the research about how Psychological Empowerment (PE) is felt by different age groups cannot be overemphasized. It is therefore suggested that further studies on the subject of PE should focus on the impact if any, that one's age and educational level can have on feelings of PE.

This study could be replicated by expanding the number of respondents to see if a larger sample size would affect the results. Furthermore, variations of this study could be done by including other countries from different culture clusters to generate greater insight into PE in terms of cultural dynamics.

\section{REFERENCES}

Ahmed, N., \& Oranye, O. (2010). Empowerment, job satisfaction and organizational commitment: a comparative analysis of nurses working in Malaysia and England. Journal of Nusing Management (18), 582-591.

Ambad, A. S., \& Bahron, A. (2012). Psychological Empowerment: the influence on organizational commitment among employees in the construction sector. The Journal of Business Management, 73-81.

Appelbaum, N. P., Dow, A., Mazmanian, P. E., KJundt, D., \& Appelbaum, E. N. (2016). The effects of power, leadership and psychological safety on resident event reporting. Medical Education, 343-350.

Arogundade, O. T., \& Arogundade, A. B. (2015). Psychological Empowerment in the Workplace: Implications for Employees' Career Satisfaction. North American Journal of Psychology, 27-36.

Awan, M. A., \& Sarfraz, N. (2013). The Impact of human capital on Company performance and the mediating effect of employee's satisfaction. Journal of Business and Management, 76-82.

Britton, D. (2000). The epistemology of the gendered organization. Gender and Society, 14(3), 418-434.

Chisamya, G., DeJaeghere, J., Kendall, N., \& Khan Marufa, A. (2012). Gender and Education for All: Progress and problems in achieving gender equity. International Journal of Educational Development, 743-756.

Corroon, M., Speizer, I. S., Fotso, J.-C., Akiode, A., Saad, A., Calhoun, L., \& Irani, L. (2014). The Role of Gender Empowerment on Reproductive Health Outcomes in Urban Nigeria. Maternal Child Health Journal, 307-315.

Dess, G., Eisner, A., Lumpkin, G., \& McNamara, G. (2014). Strategic Management: Creating Competitive Advantage. New York: McGraw-Hill.

Hofstede, G. (1980). Culture's Consequences: International Differences in Work-Related Values. Newbury Park: Sage Publications.

Hofstede, G. (2001). Culture's Consequences: comparing values, behaviors, institutions, and organizations across nations. Thousand Oaks, CA: Sage.

House, R. J., Hanges, P. J., Javidan, M., Dorfman, P. W., \& Gupta, V. (2004). Culture, Leadership, and Organizations: The GLOBE study of 62 societies. Thousand Oaks, CA: Sage Publications.

Hur, M. H. (2006). Empowerment in terms of theoritecal perspectives: Exploring a typology of the process and components accross disciplines. Journal of Community Psychology, 34(5), 523 - 540.

Ismail, A., Mohamed, H. A.-B., Sulaiman, A. Z., Mohamad, M. H., \& Yusuf, M. H. (2011). An empirical study of the relationship between transformational leadership, empowerment and organizational commitment. Business and Economic Research Journal, 2(1), 89-107.

Jeung, C.-W., \& Yoon, H. J. (2016). Leader humility and psychological empowerment: investigating contingencies. Journal of Managerial Psychology, 1122-1136.

Kunze, F., Bohm, S., \& Bruch, H. (2013). Organizational Performance Consequences of Age Diversity: Inspecting the role of diversity-friendly HP policies and top managers' negative age sterrotypes. Journal of Management Studies, 413-442.

Lakshmi, V. S., \& Peter, J. A. (2015). GENDER DIFFERENCE AND ITS IMPLICATIONS FOR ORGANIZATIONAL EFFECTIVENESS: REAL OR CONSTRUCTED. The Journal of Contemporary Management Research, 52-79.

Lawler III, E. E. (2015, May 15). Center for Effective Organization. Retrieved from University of Southern California: http://ceo.usc.edu/pdf/g08_15.pdf 
Vol: 2, Issue: 7

July/2021

https://ijbssrnet.com/index.php/ijbssr

DOI: http://dx.doi.org/10.47742/ijbssr.v2n7p1

Men, L. R. (2011). How employee empowerment influences organization-employee relationship in China. Public Relations Review, 435-437.

Meng, L., Jin, Y., \& Guo, J. (2016). Mediating and/or moderating roles of psychological empowerment. Applied Nursing Research, 104-110.

Seibert, S. E., Gang, W., \& Courtright, S. H. (2011). Antecedents and consequences of psychological and team empowerment in organizations: A meta-analytic review. Journal of Applied Psychology, 981-1003.

Speer, P. W., Peterson, N. A., Armstead, T. L., \& Allen, C. T. (2013). The Influence of Participation, Gender and Organizational Sence of Community on Psychological Empowerment: The moderating effect of income. American Journal of Community Psychology, 103-113.

Spreitzer, G. M. (1995). Psychological empowerment in workplace: Dimensions, measurement, and validation. Academy of Management Journal (39), 1442-1465.

Unterhalter, E., Heslop, J., \& Mamedu, A. (2013). Girls claiming education rights: Reflections on distribution, empowerment and gender justice in Northern Tanzania and Northern Nigeria. International Journal of Educational Developemnt, 566-575.

Valian, V. (1998). Why So Slow? the advancement of women. Cambridge, MA: The MIT Press.

Wang, J.-L., Zhang, D.-J., \& Jackson, L. A. (2013). Influence of self-esteem, locus of control, and organizational climate on psychological empowerment in a sample of Chinese teachers. Journal of Applied Psychology, 1428-1435.

Yoshino, K., \& Smith, C. (2013). Uncovering talent: A new model of inclusion. Westlake, TX: Deloitte University Press.

Yukl, G. (2013). Leadership in Organizations (8th Edition ed.). Boston: Pearson Education Inc. 